\title{
Capacity limitations in human information processing
}

\author{
STEVEN P. SHWARTZ \\ New College, Sarasota, Florida 93578
}

\begin{abstract}
The nature of processing demands during a letter-match task was investigated in an extension of the Posner and Boies (1971) paradigm. In Experiment I, a visual probe was employed in addition to an auditory probe in two different experimental conditions. The shape of the auditory probe reaction time (RT) function was similar to that found by Posner and Boies. However, in contrast to their findings, RT was greatly increased shortly after presentation of the first letter for the visual probe function. It was concluded that perceptual as well as postperceptual limitations on processing capacity exist. A second experiment provided further support for this hypothesis.
\end{abstract}

The study of attention has become increasingly prominent in the field of information processing. Results of recent studies have suggested that attentional effects are specific to mental operations which take place in the "central processor" (e.g., Hintzman, Carre, Eskridge, Owens, Shaff, \& Sparks, 1972; Keele, 1972; Keele \& Boies, 1973; Posner \& Boies, 1971; Posner \& Klein, 1973; Shiffrin, Craig, \& Cohen, 1973; Shiffrin \& Gardner, 1972). Mental operations that require processing capacity include rehearsal, response selection and initiation, memory search and comparison, mental counting, and movement control (Keele, 1973). Perceptual processing (encoding) of multiple inputs up to and including contact with long-term memory (i.e., activation of stimulus representations) appears to proceed in parallel, with unlimited processing capacity, and does not require attention.

Unfortunately, the exact nature of perceptual processing has not been clearly delineated for two reasons: (1) Most studies of attention have not clearly separated perceptual and postperceptual effects (Egeth, 1967), and (2) most studies which do not fall into Category 1 have concluded that the perceptual stage(s) does not require attention and has unlimited capacity. Therefore, interest has focused on the nature of postperceptual processing.

The secondary task technique employed by Posner and Boies (1971) offers a unique method for the assessment of processing demands during information processing. Briefly, the subject's primary task was a sequential letter match. A 1-sec interstimulus interval (ISI) separated the onset of the first letter from the onset of the

This research is based on a senior thesis submitted to the Department of Psychology, New College, in partial fulfillment of the requirements for the BA degree and was completed in March 1974. The author is grateful to thesis advisor, Dr. Donald Homa, for his patience and assistance throughout the research and preparation of this manuscript, and to Dr. Howard Egeth, Dr. David Gorfein, and David Goldman, for their contributions. The author is now at The Johns Hopkins University, Baltimore, Maryland 21218. second letter, and the subject made a "same" vs. "different" response. In addition, the subject was required to make a simple reaction time (RT) response to an auditory probe presented at a number of temporal positions during the letter-match task and was informed that this was a secondary task. Because letter-match RTs remained relatively constant as a function of the temporal position at which the probe occurred, fluctuations in probe RTs were hypothesized to reflect fluctuations in the amount of processing capacity required by the letter-match task. The same study (Posner \& Boies, 1971) had found the optimal ISI for the two letters to be $.5 \mathrm{sec}$ following presentation of the first letter, and concluded that the maximum time needed to encode the first letter was $.5 \mathrm{sec}$. Because probe RTs were relatively short during the first $.5 \mathrm{sec}$ of the letter-match task and did not begin to rise until the end of this stage, they concluded that there were no limitations on processing capacity until after encoding was complete. The generality of the latter result was demonstrated in two series of replications (Posner \& Boies, 1971; Posner \& Klein, 1973). Similar probe RT functions were found for constant ISIs of $.5,1$, and $2 \mathrm{sec}$ and for a variable ISI of $50-1,000 \mathrm{msec}$. In addition, with a constant 1 -sec ISI, this finding was replicated with first-letter exposure durations of $50-1,000 \mathrm{msec}$, although no mask followed the offset of the stimulus.

All of the studies mentioned above found nonattentive parallel perceptual processing. These findings are consistent with an unlimited perceptual processing capacity model. An alternative explanation is that, in these studies, perceptual processing capacity was not overloaded.

The present study involves a replication of the Posner and Boies (1971) study in an attempt to investigate the plausibility of this alternative explanation. The following manipulations were made: (1) The matching task was extended to a four-letter array and demands on perceptual processing capacity for one- and fourletter stimuli were compared, and (2) a visual as well 
as an auditory probe task was employed. The rationale for the latter is that, in the Posner and Boies study, the probe and letter-match tasks occurred in different modalities. Segal and Fusella (1970) found that two tasks interfered when in the same modality, but did not interfere when in different modalities. This manipulation provided a comparison of intermodality vs. intramodality limitations on processing capacity.

\section{EXPERIMENT I}

\section{Method}

Subjects. The subjects were four undergraduates from New College who received $\$ 1.50 / \mathrm{h}$ for their services. Subjects were tested individually for 5 consecutive days for approximately $1 \mathrm{~h} /$ day.

Materials and apparatus. Stimulus displays were presented on a Scientific Prototype Model GB three-channel tachistoscope. The stimuli for the matching task consisted of either a single letter or a linear array of four letters, constructed with a Leroy lettering kit (No. 3 pen). Only uppercase letters were used.

The initial stimulus (one or four letters) was presented in the lower third of the visual field, and the second stimulus (one or four letters) was presented in the middle third. Each letter subtended a visual angle of $19 \mathrm{~min}$, while the angle between the first and second letters was $31 \mathrm{~min}$. The four-letter linear arrays subtended a visual angle (horizontally) of $1.58 \mathrm{deg}$. All stimuli were presented in the horizontal center of the visual field. Two types of probes were employed. The visual probe consisted of a black disk presented in the upper third of the visual field that subtended a visual angle of $34 \mathrm{~min}$. The auditory probe was a burst of white noise generated by a GSC Model $901 \mathrm{~b}$ white-noise generator, with the controls set at $-6 \mathrm{~dB}$, and presented dichotically over headphones. Hunter Klockounters and timers were used to control interval timing and record RTs.

Procedure. The sequence of events during a given trial was as follows: Following a ready signal by the experimenter, the subject pressed a start button with his left index finger. One-half second later the initial stimulus (one or four letters) was presented [simulating the warning interval which Posner \& Boies (1971) found to be optimal] and remained on for $1 \mathrm{sec}$. Simultaneous with its offset, the second stimulus (one or four letters) was presented, and the subject made a same-different judgment by pressing the appropriate key with his right index or middle finger. In addition, on probe trials the subject made a simple RT response with his left middle finger to a probe presented at one of six temporal positions.

On half the trials, either a visual or an auditory probe was presented. The exposure durations were $150 \mathrm{msec}$ for the visual probe and approximately $40 \mathrm{msec}$ for the auditory probe at $-6 \mathrm{~dB}$. Both exposure duration for the visual probe and intensity for the auditory probe were determined by previous experimentation to produce $100 \%$ detection at all probe positions. Approximately the same six temporal positions were probed as were used by Posner and Boies (1971). The temporal positions are shown along the $x$ axes of Figures 1 and 2 . The actual probe positions used were (time in milliseconds, following the start of the trial) $176,562,674,807,996$, and 1,660

The two types of matching stimuli (one or four letters) and the two types of probes (auditory and visual) defined four experimental conditions. At the beginning of each session, the subject was instructed that the letter-match task was the primary task and that the probe task was secondary. Correct-incorrect and RT feedback were given for letter-match responses only. The first day was considered practice.

Design. Each subject received one of the four conditions on each day. The order of presentation of conditions across days was counterbalanced in a 4 by 4 Latin square, with one subject assigned to each row. Each subject received 96 trials per day, half of which required a "same" response and half a "different" response. On a randomly selected half of the trials a probe occurred, with each of the six temporal positions probed equally often in random order. On probe trials, equal numbers of "same" and "different" responses were required at each probe position and the order of "same" and "different" responses was randomly arranged. On the practice day, each subject received four blocks of 24 trials, with the four blocks representing the four experimental conditions. The order of presentation of blocks was counterbalanced in a Latin square.

The selections of letters for the matching task were determined by random sampling from a pool of 10 consonants. Where a four-letter array required a "different" response, it differed in only one position, which was randomly determined for each trial.

\section{Results and Discussion}

For each subject, a median RT for correct responses was determined for probe and letter-match RTs at each of the six probe positions. Letter-match RTs represent the time to respond "same" vs. "different" as a function of the temporal position of the probe. Figure 1 shows the mean probe RTs, averaged across subjects, for each combination of probe type (auditory vs. visual stimuli), probe position, and load (one- vs. four-letter stimuli); the corresponding data for the letter-match task is shown in Figure 2. The order of presentation of conditions across days appeared to have no systematic effects on the data, and has therefore been dropped from the analysis.

Probe RTs. An analysis of variance was performed with Type of probe, Position of probe, and Load as within-subject variables. The main effects of Type and Position were significant $[\mathrm{F}(1,3)=14.46, \quad \mathrm{MSe}=$

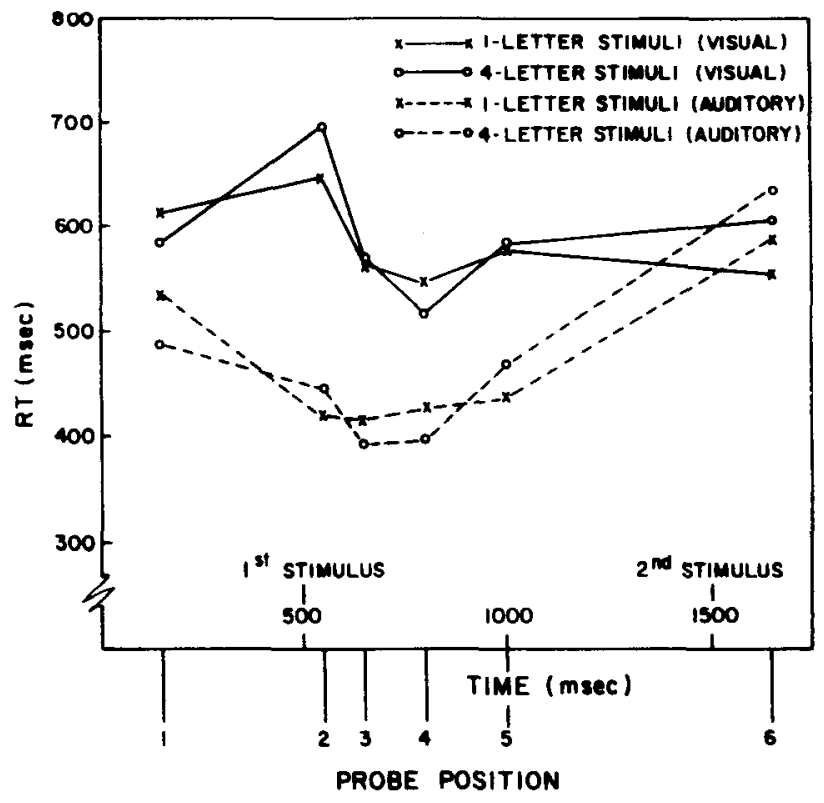

Figure 1. Visual and auditory probe RTs as a function of probe position for Experiment I. 


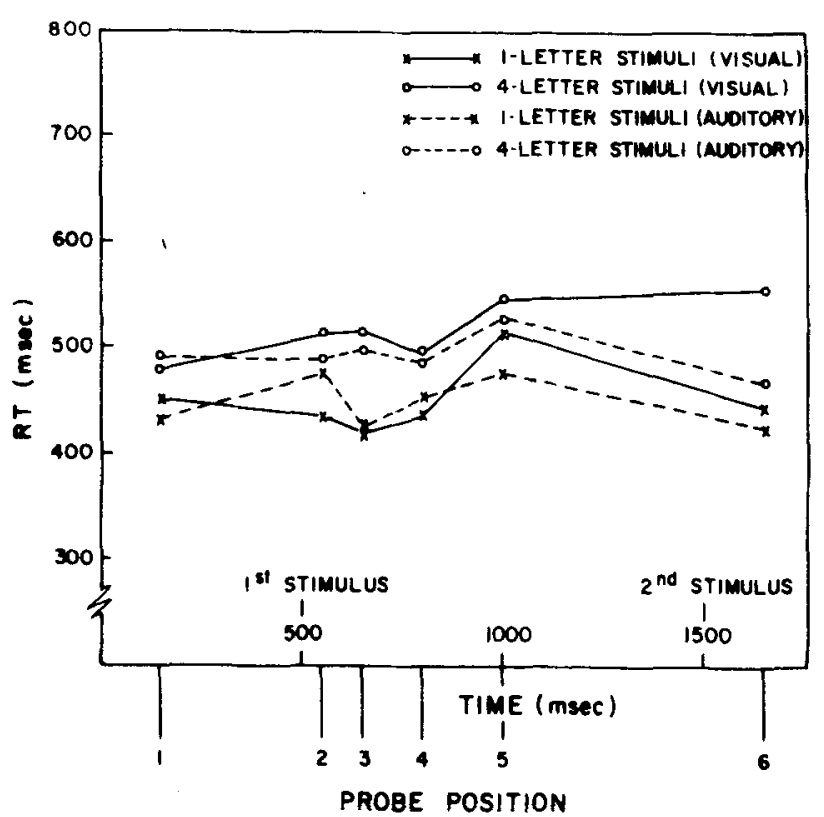

Figure 2. Letter-match RTs as a function of probe position for Experiment I.

$23,923.2, \mathrm{p}<.05$ and $\mathrm{F}(5,15)=8.78, \mathrm{MSe}=6,050.8$, $\mathrm{p}<.001]$. No other sources reached significance. As there was no main effect of Load, the data were collapsed across levels of load and individual analyses performed on the visual and auditory functions.

The shape of the auditory function replicated the Posner and Boies (1971) result, although the increase from Probe Positions 2.4 to Probe Position 5 was not significant. The RT at the three positions immediately following presentation of the first stimulus was significantly faster than during the warning interval, (i.e., Probe Position 1) $[\mathrm{t}(19)=3.75, \mathrm{p}<.01]$; however, it should be noted that, when the alditory probe occurred in the warning interval, the visual field was dark, while at all other temporal positions at which the auditory probe occurred, the visual field was illuminated from the letter-match task.

The main finding of this experiment was that the perceptual processing capacity of the letter-match task was overloaded when a visual probe occurred, but it was not overioaded when an auditory probe occurred. This result can be observed from a comparison of the auditory and visual probe RT functions during the ISI of the letter-match task (i.e., Probe Positions 2-5 of Figure 1). Analyses of variance were performed on the four probe positions in this interval. The main effect of Position was not significant for the auditory probe function, but was significant for the visual probe functions $[\mathrm{F}(3,9)=14.13, \mathrm{MSe}=1,054.8, \mathrm{p}<.001]$. A post hoc analysis, using Scheffé's method, revealed that RT at Position 2 was slower than at Positions 3 and $4(p<.001)$. A trend analysis found the linear, quadratic, and residual components to be significant $[F(1,3)=23.55, \mathrm{MSe}=578.7, \mathrm{p}<.01 ; \mathrm{F}(1,3)=17.45$, $\mathrm{MSe}=431.31, \mathrm{p}<.01 ;$ and $\mathrm{F}(1,3)=10.73, \mathrm{MSe}=$ $2,153.41, \mathrm{p}<.05$, respectively]

Thus, the visual probe data indicate that processing demands of the letter-match task are greater at Position 2 than at Positions 3 and 4. This effect cannot be explained by general alertness or arousal considerations because a similar effect was not found when an auditory probe was used. Previous results (Posner \& Boies, 1971) suggest that Probe Position 2 is in the perceptual (encoding) stage of processing. Parallel encoding appears to have taken place when the two tasks were in different modalities. When the two tasks were in the same modality, capacity was overloaded and the probe task interfered.

The overall RT superiority of the auditory stimuli to the visual stimuli in detection tasks is an oft-found result and is not surprising in view of the fact that no attempt was made at cross-modality matching of stim. ulus intensities. The convergence of the visual and auditory probe functions at Position 6 occurs when subjects are simultaneously attempting to make responses to both tasks. Any modality-specific differences may be obscured by response competition.

Letter-match RTs. An analysis of variance, similar to the one for probe RTs was performed on the lettermatch RTs from probe trials only. Letter-match RTs were longer for four-letter stimuli $(502 \mathrm{msec})$ than for one-letter stimuli $(440 \mathrm{msec})[\mathrm{F}(1,3)=36.24$, MSe $=$ $2,125.02, p<.01]$. No other sources reached significance.

The equality of one- and four-letter stimuli with respect to probe $\mathrm{RT}$ functions indicates that the number of letters in the stimulus array has no effect on the amount of processing capacity taken up by the lettermatch task. However, the superiority of single-letter stimuli over four-letter stimuli for the letter-match task implies that the individual letters of the four-letter arrays are not being processed in parallel. It is suggested that, although the amount of time required for processing of four-letter arrays is greater than for single-letter stimuli, the amount of space, or capacity, taken up by the two is equivalent.

A number of indications are present that subjects were paying primary attention to the letter-match task: (1) Letter-match RTs as a function of probe position did not differ for auditory and visual probe trials; (2) letter-match RTs were not significantly slower for probe trials than for nonprobe trials (501 vs. $486 \mathrm{msec}$, respectively); (3) the overall letter-match error rate was less than 5\%, and no systematic effects were evident across probe position; and (4) no anticipatory RTs (i.e., RTs less than $200 \mathrm{msec}$ ) were found, an indication that expectancy considerations did not enter into the shape of the probe RT function. 


\section{EXPERIMENT II}

In order to more accurately determine the shape of the visual probe RT function, a second experiment was conducted and six additional positions probed. A second manipulation involved requiring subjects to make a two-choice auditory vs. visual probe discrimination. This allowed the effects of increasing the demands on processing capacity of the secondary task to be observed. Subjects received only one of these manipulations each day. In addition, a parameter change from Experiment I to Experiment II was made: The brightness of the visual probe relative to the letter stimuli was doubled. Only single-letter stimuli were used.

\section{Method}

Subjects. Subjects were four undergraduates who did not serve in Experiment $I$ and who received $\$ 1.50 / \mathrm{h}$ for their services.

Materials and apparatus. The materials and apparatus were the same as in Experiment 1 , except that only single-letter stimuli were used and the brightness of the letter stimuli was decreased by one-half.

Procedure. After a day of practice, subjects were tested for 2 days in each of two conditions. Condition 1-simple reaction time (SRT)-was identical to the visual probe single-letter condition of Experiment I, except that an additional six positions were probed. The actual probe positions used were (time in milliseconds from the start of the trial) $176,327,507,562$, $617,674,728,807,875,996,1,660$, and 1,931 . Condition 2choice reaction time (CRT)-was identical to Experiment II, except that, on probe trials, the subject was not informed whether the probe would be visual or auditory, and the subjects's task was to make a two-choice response; i.e., a visual probe required a depression of the same button as in the SRT condition, while the auditory probe required the depression of the adjacent button. The same six temporal positions used in Experiment I were probed in the CRT condition.

Subjects received the two conditions on alternating days. As in Experiment I, subjects received 96 trials per day. The order of conditions presented across days, as well as across the four blocks of trials on the practice day, were suitably counterbalanced.

\section{Results and Discussion.}

The mean RT data, averaged across individual subject medians, for probe and letter-match RTs from the SRT condition are shown in Figure 3. The visual and auditory probe RT data for the CRT conditions are shown in Figure 4.

The results of the SRT condition confirm and clarify the shape of the visual probe RT function of Experiment I. A trend analysis performed on the visual probe RT data from the ISI of the letter-match task (i.e., Probe Positions 3-10) found only the quadratic component to be significant $[\mathrm{F}(1,3)=56.44$, MSe $=645.4$, $\mathrm{p}<.005]$. One interpretation of this U-shaped function stands out: Letter-match task demands decrease and level off during the perceptual (encoding) stage and then begin to increase as the subject begins preparation

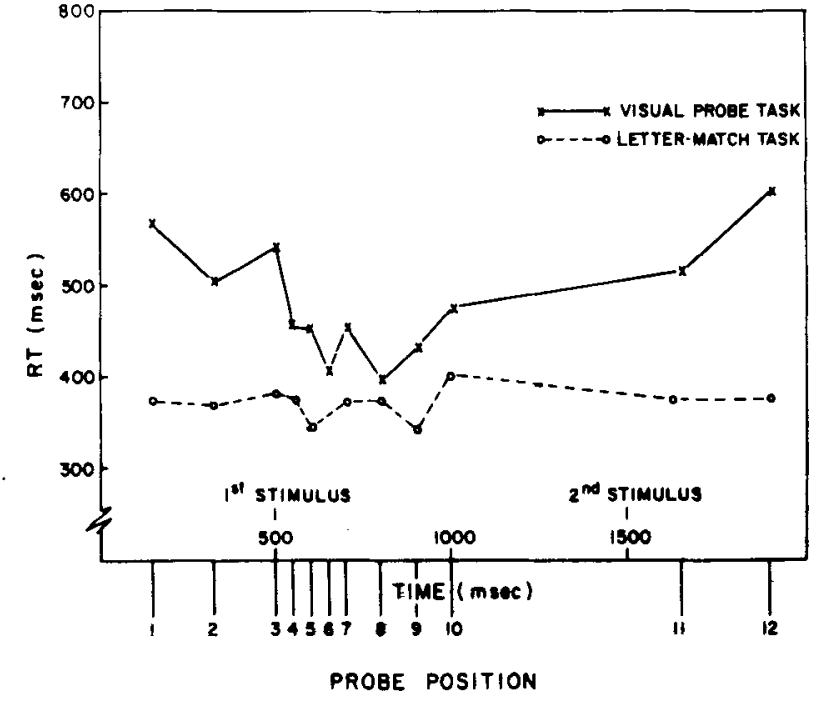

Figure 3. Visual probe and letter-match RTs as a function of probe position for the SRT condition of Experiment II.

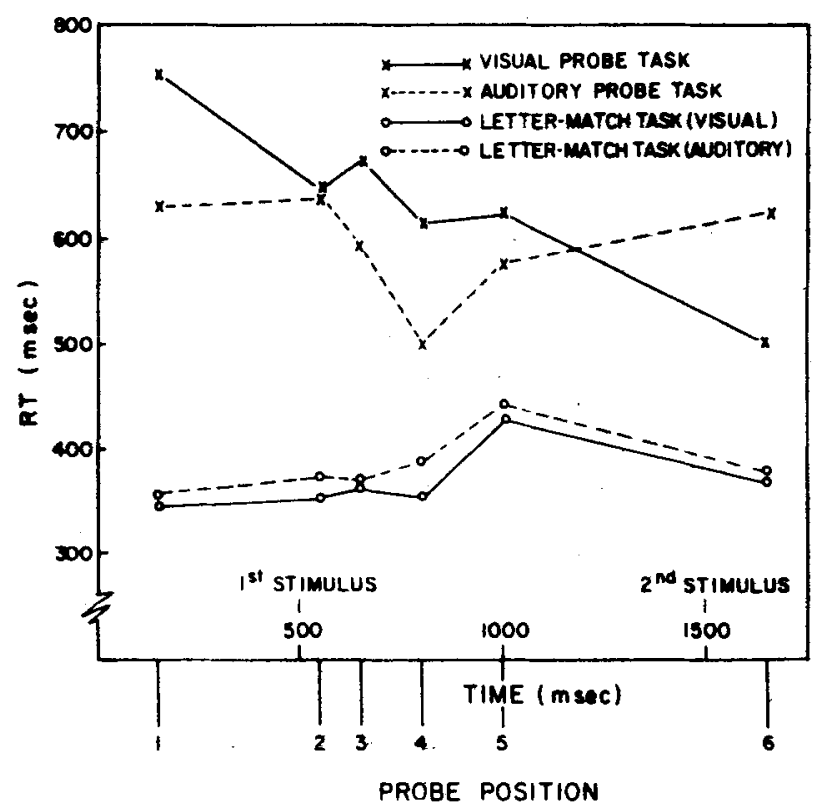

Figure 4. Visual and auditory probe and letter-match RTs as a function of probe position for the CRT condition of Experiment II.

for the second letter, i.e., generation of distinctive features for testing of the second letter, rehearsal of the first letter. etc.

The purpose of the CRT condition of Experiment II was to determine the effect of increasing the overall amount of processing capacity required by the secondary (i.e., probe) task. The shape of the auditory probe RT function from the CRT condition is similar to the visual probe RT function of Experiment I. An 
analysis of variance performed on the auditory probe RT data from the ISI of the letter-match task (i.e., Probe Positions 2-5) found the main effect of Position to be marginally significant $[\mathrm{F}(3,9)=2.83$, $\mathrm{MSe}=4,603.78$, $\mathrm{p}<.10]$. A trend analysis did not find either a significant linear or quadratic component, but did find a significant residual $[\mathrm{F}(1,3)=12.27, \mathrm{MSe}=609.2$, $\mathrm{p}<.05]$. By analogy to the conclusion drawn in Experiment $I$, the difference between the auditory functions from Experiments I and II at Probe Position 2 indicates an overload in perceptual processing capacity, in addition to the constant increase in RT across probe position, due to decision time. The error rates for each of the first four probe positions were all less than $4 \%$, which shows that the interference found at Position 2 of the auditory probe function was not due to a speedaccuracy tradeoff.

The shape of the auditory probe function is important in another respect. It could have been argued that the interference found in the encoding portion of the visual probe RT function of Experiment I was due to eye movements. However, since the auditory probe function of Experiment II showed a similar effect, eye movements cannot explain the visual probe data.

The visual probe RT function of the CRT condition is very difficult to interpret. The effect of Position in the ISI was not found to be significant, but the overall effect of Position was significant $[F(5,15)=5.32$, $\mathrm{MSe}=5,087.39, \mathrm{p}<.01]$. A post hoc analysis, using Scheffe's method, found only one significant contrast, i.e., RT at Position 6 was faster than at Positions 1.5 $(p<.05)$. This task appeared to be a very difficult one, as is evidenced by a high error rate of $12.5 \%$ on visual probe trials, compared to $5.77 \%$ on auditory trials. A ceiling effect may be present.

The shapes of the letter-match RT functions for the CRT condition were similar to those obtained in Experiment I (see Figure 4). Surprisingly, letter-match RTs in the visual probe condition were slightly faster overall than in the auditory probe condition: 369 and $385 \mathrm{msec}$, respectively $[\mathrm{F}(1,3)=22.49, \mathrm{MSe}=130.94, \mathrm{p}<.01]$. The reason for this RT difference is unclear; however, it is likely that subjects used different strategies on visual and auditory probe trials because of the difficulty of the visual probe task.

The relative difference in brightness between the SRT condition and the visual probe condition of Experiment I produced a constant difference in RT over ISI (457 and $483 \mathrm{msec}$, respectively), and did not appear to alter the shape of the function over this interval. However, no strong conclusions can be drawn from this result because different subjects were used in the two experiments.

\section{CONCLUSIONS}

The existence of limited capacity in a given stage of information processing is demonstrated by interference between two or more simultaneous inputs which occur wholly within that stage.

Limited capacity has previously been convincingly demonstrated for postperceptual stages, i.e., those stages involving mental operations belonging to the central processor. The Stroop paradigm demonstrates this effect clearly. When a color word is printed in another color of ink and the subjects' task is to name the ink color, a verbalization response to the color word is automatically initiated along with the initialization of the verbalization of the ink color. This effect can be inferred to be postperceptual because interference occurs only after meaningful information, i.e., a verbal representation, has been extracted from the stimulus.

The present experiment has demonstrated limited capacity in a perceptual (encoding) stage. The visual probe functions obtained from Experiment $I$ and the SRT condition of Experiment Il demonstrate interference between the visual probe and letter-match tasks which clearly occurred at the beginning of the encoding stages of the letter-match task.

Posner and Klein (1973) have suggested that consciousness is closely related to the limited-capacity aspects of the information processing system. However, they consider limited capacity to be a property only of later processing stages. The present study indicates that limited capacity exists in earlier stages also.

Keele (1973) has defined two types of limitations on information processing-limitations of space and limitations of time. The interference found in the present study between the probe and the letter-match tasks is an example of the former. When two tasks are performed in parallel and their combined capacity demands are greater than the capacity available, the performance of at least one of the tasks must suffer. The RT superiority of single-letter stimuli over fourletter stimuli in the letter-match task is also an example of a limitation of space. Because capacity limitations made parallel processing of the four-letter stimuli impossible, the array was processed serially, rendering capacity demands for one- and four-letter stimuli equal, though more time was required to process the fourletter stimuli.

Perhaps the function of consciousness is to maximize the efficiency of utilization of the space and time available to the information processing system. When the system is threatened with capacity overload, due to limitations of space, consciousness acts to serialize, attenuate, or reject irrelevant signals in order to prevent overload. Where limitations of time do not allow full processing of a signal, consciousness may act to regulate the speed of processing, possibly at the expense of efficiency (Posner, Klein, Summers, \& Buggie, 1973). Thus, limitations of space require a more passive, safeguarding aspect of consciousness, while limitations of time require active regulation of information processing in order to increase the efficiency of processing. 


\section{REFERENCES}

Egeth, H. E. Selective attention, Psychological Bulletin, $1967,67,41-57$.

Hintzman, D. L., Carre, F. A., Eskridge, V. L., Owens, A. M., Shaff, S. S., \& Sparks, M. E. "Stroop effect: Input or output phenomenon?" Journal of Experimental Psychology, 1972. 95, 245-274.

KeELE. S. W. Attentional demands of memory retrieval. Journal of Experimental Psychology, 1972, 93, 245-248.

KeEle, S. W. Attention and human performance. Pacific Palisades, Calif: Goodyear, 1973.

KEele, S. W., \& Bores, S. J. Processing demands of sequential information. Memory \& Cognition, 1973, 1, 85-90.

PosNer, M. I., \& Boles, S. J. Components of attention. Psychological Review, 1971, 78, 391-408.

Posner. M. I.. \& KLein, R. On the functions of consciousness.
In S. K. Kornblum (Ed.), Attention and performance IV. Amsterdam: North-Holland, 1973.

Posner, M. I., Klein, R., Summers, J., \& Buggie, S. On the selection of signals. Memory \& Cognition, 1973, 1, 2-12.

SEGAl, S. J., \& Fusella, V. The influence of imaged pictures and sounds on detection of visual and auditory signals. Journal of Experimental Psychology, 1970, 83, 458.464.

Shiffrin, R. M., \& Gardner, G. T. Visual processing capacity and attentional control. Journal of Experimental Psychology, 1972, 93, 72-82.

Shiffrin, R. M., Craig, J. C., \& Cohen, E. On the degree of attention and capacity limitations in tactile processing. Perception \& Psychophysics, 1973, 13, 328-336.

(Received for publication January 8, 1976; revision accepted April 1, 1976.) 